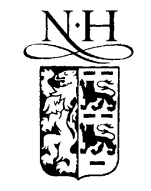

ELSEVIER

\title{
Amorphous-silicon thin-film transistors deposited by VHF-PECVD and hot-wire CVD
}

\author{
B. Stannowski ${ }^{\text {a,* }}$, R.E.I. Schropp ${ }^{\text {a }}$, R.B. Wehrspohn ${ }^{\text {b }}$, M.J. Powell ${ }^{\text {c }}$ \\ a Physics of Devices, Debye Institute, Utrecht University, P.O. Box 80000, 3508 TA Utrecht, The Netherlands \\ b Max-Planck-Institute für Mikrostrukturphysik, Weinberg 2, 06120 Halle, Germany \\ ${ }^{\mathrm{c}}$ Philips Research Laboratories, Redhill, Surrey, RH1 5HA, UK
}

\begin{abstract}
We investigate the impact of new growth techniques on the mobility and stability of amorphous silicon (a-Si:H) thin film transistors (TFTs). It was suggested that the key parameter controlling the field-effect mobility and stability is the intrinsic mechanical stress in the a-Si:H layer. We study a series of bottom-gate TFTs incorporating a-Si:H deposited by VHF PECVD and hot-wire CVD. All TFTs exhibit good characteristics with mobilities of $0.6-0.7 \mathrm{~cm}^{2} / \mathrm{V}$ s. The mean activation energy $E_{\mathrm{A}}$ and the slope of the barrier-height distribution $k_{\mathrm{B}} T_{0}$ for defect creation in the a-Si:H are determined. $E_{\mathrm{A}}$ correlates to the intrinsic stress. (c) 2002 Elsevier Science B.V. All rights reserved.
\end{abstract}

PACS: 85.30.tv; 81.15.gh; 73.61.jc; 73.20.-r

\section{Introduction}

Amorphous silicon (a-Si:H) thin film transistors (TFT), commonly deposited by plasma enhance chemical vapor deposition (PECVD) at $13.56 \mathrm{MHz}$, are widely used as pixel-switching devices in largearea electronics. The low field-effect mobility $\left(<1 \mathrm{~cm}^{2} / \mathrm{V} \mathrm{s}\right)$ and the limited stability under gatebias stress, due to defect creation in the a-Si:H, complicates the utilization in applications where high performance is demanded, such as OLED displays and column/row-addressing circuitry. While the low mobility is attributed to the inherent disorder of a-Si:H, the microscopic details of the

\footnotetext{
${ }^{*}$ Corresponding author.

E-mail address: b.stannowski@phys.uu.nl (B. Stannowski).
}

defect-creation mechanism (Staebler-Wronski effect) are still elusive.

TFTs incorporating PECVD a-Si:H with high compressive stress exhibited a poor stability [1]. This was explained with a high fraction of short (compressed) $\mathrm{Si}-\mathrm{Si}$ bonds, of which the energy levels are located in the valence-band tail, which tend to break under charge accumulation, thereby forming dangling-bond defects. This process is thermally activated with an exponential distribution of barrier heights.

Since 'device-quality' a-Si:H usually has high compressive stress, combining a high field-effect mobility with a high TFT stability seems to be contradictious. Therefore, alternative deposition techniques, such as very-high frequency (VHF) PECVD [2] and hot-wire (HW) CVD [3] have been used for TFT deposition. It could be shown that 
TFTs with a high stability, maintaining a high mobility, are feasible [4]. We now present a comprehensive study of the stability and mobility of VHF and hot-wire TFTs.

\section{Amorphous silicon deposition and material prop- erties}

The a-Si:H layers and TFTs for this study were deposited in the ultrahigh vacuum multichamber deposition system ASTER (electrode area $177 \mathrm{~cm}^{2}$ ). Plasma excitation frequencies of 13.56, 30, 50, and $70 \mathrm{MHz}$ were used. The substrate temperature was $250{ }^{\circ} \mathrm{C}$; we used hydrogendiluted silane $\left(\mathrm{SiH}_{4} / \mathrm{H}_{2}=30 \mathrm{sccm} / 30 \mathrm{sccm}\right)$. In order to remain in the $\alpha$-regime with a deposition rate around $0.2 \mathrm{~nm} / \mathrm{s}$ we reduced the pressure and the plasma power with increasing frequency.

Additionally, a-Si:H was deposited by HWCVD. Two tantalum filaments heated to $1900{ }^{\circ} \mathrm{C}$ and mounted $5 \mathrm{~cm}$ underneath parallel to the substrate were utilized to catalytically decompose pure silane. The substrate temperature was $340{ }^{\circ} \mathrm{C}$. The deposition rate was $1.34 \mathrm{~nm} / \mathrm{s}$.

From the Si-H stretching mode at $2000 \mathrm{~cm}^{-1}$ of infrared absorption spectra (FTIR) we determined a hydrogen concentration of 11-12 at.\% for the plasma a-Si:H, slightly decreasing with increasing frequency. The hot-wire a-Si:H had a hydrogen content of 8.3 at.\%. We attributed the lower value to the higher substrate temperature. A shoulder at
$2090 \mathrm{~cm}^{-1}$ in the FTIR spectrum is generally attributed to $\mathrm{Si}-\mathrm{H}_{2}$ or $\mathrm{Si}-\mathrm{H}$ vibrations on internal surfaces. The spectra of the plasma a-Si:H show very little microstructure, while for the hot-wire material a microstructure parameter of $R^{*}=I_{2090}$ / $\left(I_{2000}+I_{2090}\right)=0.2$ indicates $\mathrm{Si}-\mathrm{H}_{2}$ and/or $\mathrm{mi}$ crovoids.

The mechanical stress in $150-320 \mathrm{~nm}$ thick aSi:H films on ultra flat thin glass substrates (Schott D263) was calculated by the beam-bending method from the parabolic curvature of the substrate [5], measured with a Dektak profilometer and crosschecked with a laser-scanning method [1]. To obtain the intrinsic stress $\sigma_{\mathrm{i}}$ in the a-Si:H we subtracted the stress component due to the mismatch of the thermal expansion coefficient of the substrate and the film, $\sigma_{\text {th }}=E_{\mathrm{f}} /\left(1-v_{\mathrm{f}}\right) \cdot\left(a_{\mathrm{s}}-a_{\mathrm{f}}\right)$. $\left(T_{\mathrm{s}}-T_{\text {room }}\right)$. We used $a_{\mathrm{s}}=7.2 \times 10^{-6} \mathrm{~K}^{-1}, a_{\mathrm{f}}=$ $4 \times 10^{-6} \mathrm{~K}^{-1}$, and $v_{\mathrm{f}}=0.2 \quad[1]$. The Young's modulus was taken as $E_{\mathrm{f}}=140 \mathrm{GPa}$ for all a-Si:H films. This is expected for PECVD a-Si:H with 12 at.\% hydrogen [1]. Literature values for HWCVD a-Si:H with around 8 at.\% hydrogen vary between 110 and $140 \mathrm{GPa}$ ([6] and references therein). For our samples $\sigma_{\text {th }}$ was 130 and $180 \mathrm{MPa}$ for $T_{\mathrm{s}}=250$ and $340{ }^{\circ} \mathrm{C}$, respectively. The resulting intrinsic (compressive) stress $\sigma_{\mathrm{i}}$ ranges between 90 and $540 \mathrm{MPa}$. We estimate a relative error of $\pm 50 \mathrm{MPa}$, mainly due to the thickness inhomogeneity of the a-Si:H films. An overview over the deposition parameters and material properties is given in Table 1.

Deposition parameters and properties of PECVD and HWCVD a-Si:H layers and TFTs

\begin{tabular}{|c|c|c|c|c|c|}
\hline & PECVI & & & & HW \\
\hline \multicolumn{6}{|l|}{$a-S i: H$} \\
\hline$f(\mathrm{MHz})$ & 13.56 & 30 & 50 & 70 & - \\
\hline$p(\mathrm{~Pa})$ & 40 & 30 & 20 & 10 & 2 \\
\hline$P\left(\mathrm{~mW} / \mathrm{cm}^{2}\right)$ & 57 & 40 & 28 & 11 & - \\
\hline Thickness (nm) & 244 & 151 & 219 & 320 & 268 \\
\hline$r_{\mathrm{dep}}(\mathrm{nm} / \mathrm{s})$ & 0.20 & 0.13 & 0.17 & 0.27 & 1.34 \\
\hline$[\mathrm{H}]($ at. $\%)$ & 11.9 & 11.7 & 11.4 & 10.7 & 8.3 \\
\hline$\sigma_{i}(\mathrm{MPa})$ & 540 & 255 & 450 & 360 & 85 \\
\hline \multicolumn{6}{|l|}{$T F T$} \\
\hline$\mu_{\mathrm{FE}}\left(\mathrm{cm}^{2} / \mathrm{V} \mathrm{s}\right)$ & 0.64 & 0.68 & 0.72 & 0.70 & 0.61 \\
\hline$k_{\mathrm{B}} T_{0}(\mathrm{meV})$ & 63 & 64 & 65 & 65 & 63 \\
\hline$E_{\mathrm{A}}(\mathrm{eV})$ & 0.918 & 0.929 & 0.916 & 0.922 & 0.937 \\
\hline
\end{tabular}




\section{Thin film transistors}

The a-Si:H layers were incorporated in bottomgate TFTs with a nitrogen-rich PECVD a-SiN gate dielectric as described elsewhere [7]. The device structure was: glass substrate/Cr gate contact/ $300 \mathrm{~nm}$ a-SiN ${ }_{x} / 200 \mathrm{~nm}$ a-Si:H/50 nm n ${ }^{+}$a-Si:H/ $\mathrm{Cr}-\mathrm{Al}$ source-drain contacts. Different layers were deposited in dedicated chambers of the multichamber system. Inverted-staggered TFTs were made by conventional back-channel etching. The channel dimensions were $W / L=11520 \mu \mathrm{m} /$ $50 \mu \mathrm{m}$.

Fig. 1 shows the linear transfer characteristics of some TFTs. All devices exhibit good characteristics, with a low off current, a steep subthreshold swing of $S \sim 0.3 \mathrm{~V} / \mathrm{dec}$, and without charge trapping. The initial threshold voltages were $V_{t}^{\text {ini }}=(2 \pm 0.2) \mathrm{V}$ with very little spread between different devices. The field-effect mobilities reach $0.72 \mathrm{~cm}^{2} / \mathrm{V} \mathrm{s}$ exhibiting a slight increase with increasing plasma frequency. Values determined in saturation regime $\left(V_{\mathrm{g}}=V_{\mathrm{sd}}\right)$ did not differ substantially. Table 1 summarizes the TFT properties.

For determining the TFT stability, we applied a gate voltage of $V_{\mathrm{g}}=25 \mathrm{~V}$ at temperatures between 312 and $370 \mathrm{~K}$ for up to $28 \mathrm{~h}$. To determine the threshold voltage $V_{\mathrm{t}}$, the bias stress was briefly interrupted to measure the linear transfer charac-

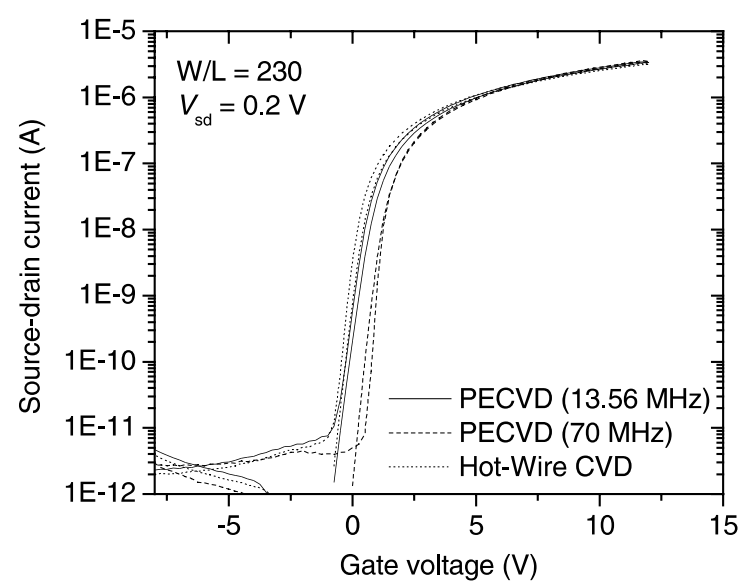

Fig. 1. Linear transfer characteristics (sweeping in both directions) of VHF-PECVD and HWCVD a-Si:H TFTs. teristics at the stressing temperature. Fig. 2 shows the result of the $13.56 \mathrm{MHz}$ sample. The data was interpreted within the framework of the thermalization-energy concept [8] by fitting a stretched hyperbola function $[1,8]$ to the relative thresholdvoltage shift

$$
\begin{aligned}
& \left(V_{t}-V_{\mathrm{t}}^{\mathrm{ini}}\right) /\left(V_{\mathrm{g}}-V_{\mathrm{t}}^{\mathrm{ini}}\right) \\
& \quad=1-\left(\exp \left[\left(E_{\mathrm{th}}-E_{\mathrm{A}}\right) / k_{\mathrm{B}} T_{0}\right]+1\right)^{-1 /(\alpha-1)},
\end{aligned}
$$

with $E_{\mathrm{th}}=k_{\mathrm{B}} T \ln \left(v_{0} t\right)$ being the thermalization energy. The equation describes dispersive defect creation, thermally activated with an exponential distribution of barrier heights, and a superlinear $(\alpha)$ dependence on the band-tail carrier density. The best overlap of data sets from different temperatures was obtained with an 'attempt-to-break' frequency of $v_{0}=10^{9} \mathrm{~s}^{-1}$, slightly lower than the $10^{10} \mathrm{~s}^{-1}$ as previously found for a-Si:H TFTs $[4,8]$. The best fitting results were obtained with $\alpha=1.5$. A discussion on the meaning of this parameter is found elsewhere [9].

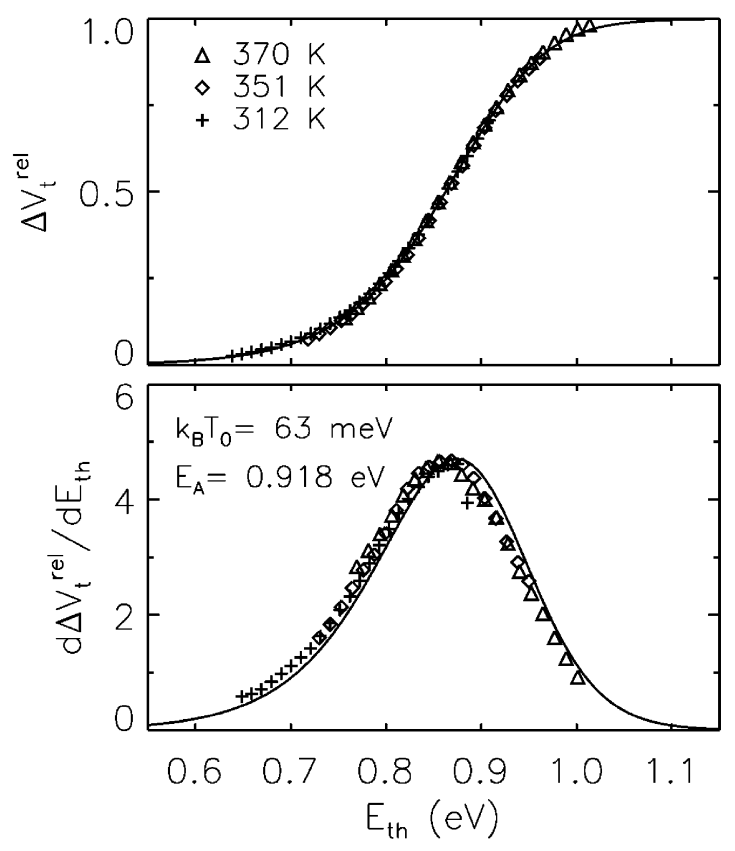

Fig. 2. Relative threshold voltage shift versus thermalization energy (top), and the derivative (bottom), for the $13.56 \mathrm{MHz}$ PECVD a-Si:H TFT; experimental data $\left(v_{0}=10^{9} \mathrm{~s}^{-1}\right)$ and a least-squares fit with a stretched hyperbola $(\alpha=1.5)$. 
Physically meaningful parameters, such as the mean activation energy for defect creation, $E_{\mathrm{A}}$, and the slope of the barrier-height distribution, $k_{\mathrm{B}} T_{0}$ can be extracted from the derivative of $\Delta V_{\mathrm{t}}\left(E_{\mathrm{th}}\right)$, namely, the peak position and its width, respectively (Fig. 2). We found $k_{\mathrm{B}} T_{0}$ to be between 63 and $65 \mathrm{meV}$, comparable to $k_{\mathrm{B}} T_{0} \mathrm{~s}$ as previously reported for PECVD and HWCVD a-Si:H TFTs with these mobilities $[1,4]$. The activation energy $E_{\mathrm{A}}$ ranges between 0.916 and $0.937 \mathrm{eV} \pm 0.005 \mathrm{eV}$.

Fig. 3(a) shows $E_{\mathrm{A}}$ versus $\sigma_{\mathrm{i}}$. As expected, a trend towards higher $E_{\mathrm{A}}$ for lower compressive stress is present. In order to cross-check this, we performed Raman spectroscopy (excitation wavelength $514.5 \mathrm{~nm}$ ) on the a-Si:H films. The peak position of the transverse-optic (TO) mode $\omega_{\mathrm{TO}}$, determined within an accuracy of $\pm 0.5 \mathrm{~cm}^{-1}$, was reported to shift towards higher wave numbers for higher compressive stress [10]. Fig. 3(b) shows that $E_{\mathrm{A}}$ indeed decrease with increasing $\omega_{\mathrm{TO}}$, confirming the trend in Fig. 3(a).
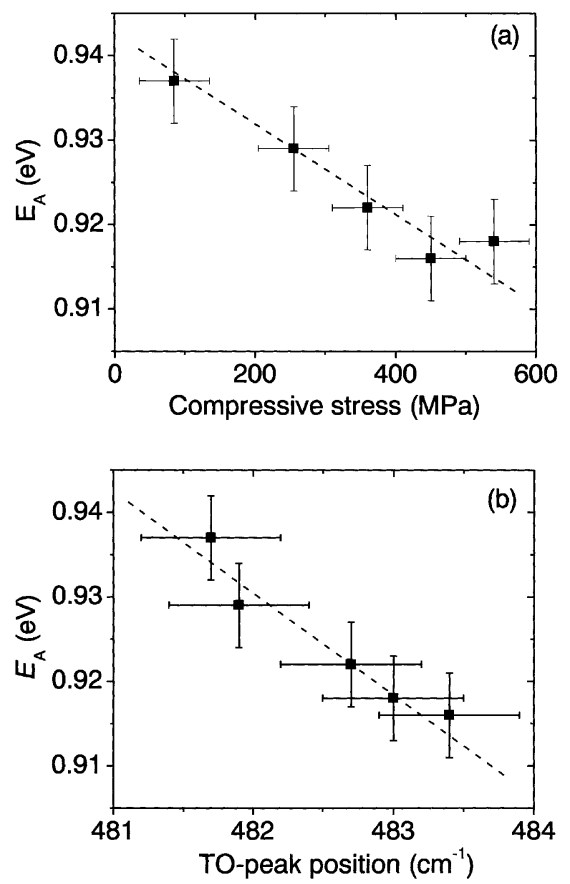

Fig. 3. Activation energy for defect creation versus (a) intrinsic stress and (b) the peak position of the TO-like band in Raman spectra.

\section{Discussion}

At first sight, the TFTs seem to be very similar, with the same characteristics, threshold voltages and field-effect mobilities in a narrow range 0.61$0.72 \mathrm{~cm}^{2} / \mathrm{V}$ s. This is a success on its own, since it demonstrates that HWCVD a-Si:H, deposited with a much higher growth rate, can replace PECVD a-Si:H in TFTs with similar mobility and an even better stability. The slightly lower value of the mobility of the HWCVD a-Si:H TFT can be explained with the higher $R^{*}$ and a higher Urbach energy of $E_{0}=55 \mathrm{meV}$, as derived from Constant Photocurrent Method (CPM) absorption spectra. The PECVD a-Si:H, in comparison, have $R^{*}<$ 0.05 and $E_{0} \sim 50 \mathrm{meV}$. In the case of the PECVD TFTs, the slight increase of $\mu_{\mathrm{FE}}$ with increasing plasma frequency and decreasing power is supposed to be due to the softer plasma conditions resulting in less a-Si:H/a-SiN ${ }_{x}$ interface damage, thus a lower trap density.

The dispersion parameter $k_{\mathrm{B}} T_{0}$ is assumed to be dependent on the degree of order of the material in the channel. Similarly, the width of the TO-like band is linked to the bond-angle distribution (near-range order) in the Si network [11]. Since also the field-effect mobility was found to be related to the material order [12], a correlation between these three parameters could be expected. However, we found no correlation, which might be due to the low spread in experimental data.

Compact 'device-quality' a-Si:H is generally found to be under compressive stress. Less dense a-Si:H, as deposited by PECVD in the $\gamma^{\prime}$-regime at high deposition rates, tends to contain microvoids and has tensile stress. In plasma a-Si:H, the origin of compressive stress is commonly ascribed to the ion bombardment. At deposition temperatures $<300{ }^{\circ} \mathrm{C}$ the ion energy is needed to increase the surface mobility of growth precursors and to enable the cross-linking process for obtaining a dense network. Excessive ion energy leads to ion implantation a few monolayers underneath the surface; thus, the surplus of $\mathrm{Si}$ atoms results in a densification and compressive stress [13]. Hence, the variation of stress in our PECVD films can be explained with a variation in ion energies due to the different deposition conditions. In the case of 
HWCVD no ion bombardment is present; thus, another mechanism must be responsible for inducing compressive stress. For remote-plasma deposition the compressive stress was ascribed to the invasive incorporation of hydrogen into the rigid Si network [14]. Since the key features are similar in HWCVD (high atomic hydrogen flux, no ion bombardment), the same effect might hold.

Even though the trend in Fig. 3(a) is obvious, HWCVD a-Si:H deposited with higher $T_{\mathrm{s}}$ cannot be simply included into the diagram. We find $\sigma_{\mathrm{i}}=170 \mathrm{MPa}$ in hot-wire a-Si:H deposited at 430 ${ }^{\circ} \mathrm{C}$. TFTs with this a-Si:H reach $E_{\mathrm{A}}>1 \mathrm{eV}$ [4]. Plotting it in Fig 3(a) would lead to a sharp peak around $200 \mathrm{MPa}$, which was indeed found in [1] for PECVD TFTs. However, while the intrinsic stress may be the parameter primarily determining $E_{\mathrm{A}}$ for PECVD a-Si:H, we doubt that the intrinsic stress is in general the only parameter determining $E_{\mathrm{A}}$, as becomes clear by considering high- $T$ HWCVD a-Si:H.

It was shown [15] that 'device-quality' HWCVD a-Si:H with a low hydrogen content is highly inhomogeneous containing microvoids and hydrogen clusters, hence, the origin of a macroscopic parameter, such as the intrinsic stress, is complex and might be misleading. To explain the superior stability of HWCVD a-Si:H deposited at high $T_{\mathrm{s}}$, the inhomogeneous structure and/or hydrogen distribution might play a direct role. The intrinsic stress may be an indirect parameter or be dominant for low- $T$ a-Si:H only. However, more detailed conclusion are beyond the scope of this paper and require a more thorough study.

\section{Conclusions}

We demonstrated that state-of-the-art TFTs with mobilities of $0.6-0.7 \mathrm{~cm}^{2} / \mathrm{V}$ s can be made by using VHF-PECVD and HWCVD a-Si:H. In particular, high deposition rate hot-wire a-Si:H leads to TFTs with comparable characteristics and even superior stability.

We found an increasing TFT stability with decreasing compressive stress in the a-Si:H. Al- though for HWCVD a-Si:H the concept of intrinsic stress being the key parameter controlling the stability seems problematic, our results confirm the previously reported data of PECVD a-Si:H TFTs.

\section{Acknowledgements}

We would like to thank J.A. Chapman for lithographie and etching, J. Groenewoud for film depositions, A.M. Brockhoff for performing Raman spectroscopy, and J.K. Rath for stimulating discussions. We gratefully acknowledge financing from the STW Technical Foundation and the Netherlands Agency for Energy and the Environment (NOVEM).

\section{References}

[1] R.B. Wehrspohn, S.C. Deane, I.D. French, J. Hewett, M.J. Powell, J. Robertson, J. Appl. Phys. 87 (2000) 144.

[2] H. Meiling, J. Bezemer, R.E.I. Schropp, W.F. van der Weg, Mater. Res. Soc. Symp. Proc. 467 (1997) 459.

[3] H. Meiling, R.E.I. Schropp, Appl. Phys. Lett. 70 (1997) 2681.

[4] B. Stannowski, A. Nascetti, R.E.I. Schropp, Appl. Phys. Lett. 75 (1999) 3674.

[5] L.I. Maissel, R. Glang, Handbook of Thin-Film Technology, McGraw-Hill, New York, 1970.

[6] E. Spanakis, E. Stratakis, P. Tzanetakis, Q. Wang, J. Appl. Phys. 89 (2001) 4294.

[7] B. Stannowski, R.E.I. Schropp, Mater. Res. Soc. Symp. Proc. 557 (1999) 659.

[8] S.C. Deane, R.B. Wehrspohn, M.J. Powell, Phys. Rev. B 58 (1998) 12625.

[9] R.B. Wehrspohn, S.C. Deane, M.J. Powell, these Proceedings, p. 492.

[10] Y. Hishikawa, J. Appl. Phys. 62 (1987) 3150.

[11] D. Beeman, R. Tsu, M.F. Thorpe, Phys. Rev. B 32 (1985) 874.

[12] S. Sherman, S. Wagner, R.A. Gottscho, Appl. Phys. Lett. 69 (1996) 3242

[13] E.A.G. Hamers, W.G.J.H.M. van Sark, J. Bezemer, H. Meiling, W.F. van der Weg, J. Non-Cryst. Solids 226 (1998) 205.

[14] K.S. Stevens, N.M. Jackson, J. Appl. Phys. 71 (1992) 2628.

[15] Y. Wu, J.T. Stephen, D.X. Han, J.M. Rutland, R.S. Crandall, A.H. Mahan, Phys. Rev. Lett. 77 (1996) 2049. 